\title{
Comparison of a Rasch Model Scale and the Grade-Equivalent Scale for Vertical Equating of Test Scores
}

\author{
Thomas R. Guskey \\ University of Kentucky
}

\begin{abstract}
Wright (1977) outlined procedures for equating tests and test scores using the Rasch model. This paper summarizes the results of a study in which those Rasch model procedures are used to calibrate and then to link vertically six levels of the Reading Comprehension Test of the Iowa Tests of Basic Skills. The derived Rasch ability scale estimates are then compared to norm-referenced, grade-equivalent scale estimates for scores across the test levels. The results of these comparisons suggest that where discrepancies in the two scales emerge, the more accurate and perhaps more useful measure is provided by the Rasch scale.
\end{abstract}

Tests are traditionally equated by administering them to a common sample of people and then by defining as equivalent those scores that correspond to a common percentile rank. One of the most widely used scales in which this equivalency of scores is expressed is the grade-equivalent scale. Normative scales, such as the gradeequivalent scale, enjoy a continuing popularity among contemporary measurement practitioners, primarily because of their supposed simplicity and directness of meaning. Yet as Angoff (1971) points out, the simplicity of grade equivalents and other such scales is far more apparent than real, and truly simple scales may

\footnotetext{
APPLIED PSYCHOLOGICAL MEASUREMENT Vol. 5, No. 2, Spring 1981, pp. 187-201

(C) Copyright 1981 Applied Psychological Measurement Inc. 0146-6216/81/020187-15\$1.75
}

well be those for which there has been no attempt to capitalize on the use of direct meaning.

A promising alternative for equating tests and test scores is through use of the Rasch model. The Rasch model is a latent trait model, with extensive possibilities for solving measurement problems. Of all latent trait models proposed for person measurement, the Rasch model has the fewest components: just one ability parameter for each person and one difficulty parameter for each item. These parameters represent the positions of persons and items on the latent variable that they share.

Though the Rasch model offers a precise and very economical approach to the scaling of tests and test items, it has yet received only limited consideration in actual school settings. One of the most useful aspects of the model is the interval scaling it provides for both test scores and individual test items on the underlying latent trait dimension. By using the interval scales provided by the model, different tests measuring the same latent trait, or alternate forms of the same test, can theoretically be linked by including a set of common items between the tests.

Wright (1977) outlined procedures for linking tests based upon common items. According to Wright, as few as 10 good items are all that are necessary to insure linking quality. In order to link tests that include these common items, each level or form of the test is first analyzed using 
Rasch procedures. Through this analysis a pair of independent estimates of difficulty are produced for each item that is common to the pair of tests. According to the Rasch model, these estimates of difficulty are statistically equivalent except for a single constant of translation that is the same for all items in both tests. In other words, this constant of translation defines the difference in difficulty on the underlying latent trait of the two tests as collections of items. Such a property makes estimation of the translation factor between the pair of tests a very easy operation and, in addition, provides a way to estimate the goodness of the equating. Furthermore, Rasch model item analysis provides an indication of those individual items that may be ambiguous, inappropriate, or otherwise invalid.

This study was designed to explore the feasibility of Rasch model procedures for equating test scores and to compare the resulting scale measures to traditional norm-referenced, gradeequivalent scale scores.

\section{Method}

\section{Data}

The data for this study were made available by the Department of Research and Evaluation of the Chicago Board of Education. The Iowa Tests of Basic Skills (ITBS), Form 6, is administered annually to children enrolled in Chicago public schools as part of a citywide testing program. The Reading Comprehension Test of the ITBS, the test upon which this study focused, consists of written selections varying in length from a few sentences to a full page. Each selection is followed by a series of 4 to 21 multiple-choice items. There are 178 items in the test, relating to 20 reading selections. The selections are ordered sequentially in the test by levels designed to correspond roughly to chronological age. Each student is typically administered the level of the test most appropriate in content and difficulty for his or her level of educational development. The six levels of the test included in this study were Levels 9 through 14 . Level 9 is intended to be most appropriate for children 9 years old, and so on. Each level starts and ends at a different point in the sequence of passages. The arrangement of passages and items per level is illustrated in Table 1.

\section{Item Calibration}

The first step in this study was to analyze and to calibrate separately each level of the test using Rasch methods. To do this, a sample of 6,000 pupils who had taken the test during 1976 was drawn: 1,000 pupils at each of the six levels. The sample was randomly selected from pupils with scores between $50 \%$ and $80 \%$ correct. Restricting the sample selection in this fashion is theoretically unnecessary; earlier studies have demonstrated that the Rasch model can yield virtually identical test calibration results for student groups of very dissimilar achievement levels (Wright, 1968). However, since the purpose of this study was not to validate the test or test items but rather to investigate the utility of test score equating procedures, pupils were selected for whom each test level was most appropriate.

Each level was analyzed using the BICAL program (Wright \& Mead, 1977) for calibrating items and scales with the Rasch model. Each item in the test was then screened with respect to its conformity to the Rasch model. Conformity of an item to the Rasch model was evaluated by fitting the model to the data, calculating the residuals in the data from the values expected from the model, and then examining these residuals. When the residuals are collected over persons for an item, the magnitude of their mean square provides an index of the extent to which the item is fitted (Mead, 1976; Wright, Mead, \& Draba, 1976).

Table 2 lists the fit statistic mean and standard deviation for items in each level of the test. This table illustrates that within each level, the fit mean square statistic was very near its expected value of 1.00 . Therefore, each level of the test, as a set of items, appeared to fit the model well. 
Table 1

Arrangement of Items Per Level on the Reading Comprehension Test Item Numbers Items Per Passage

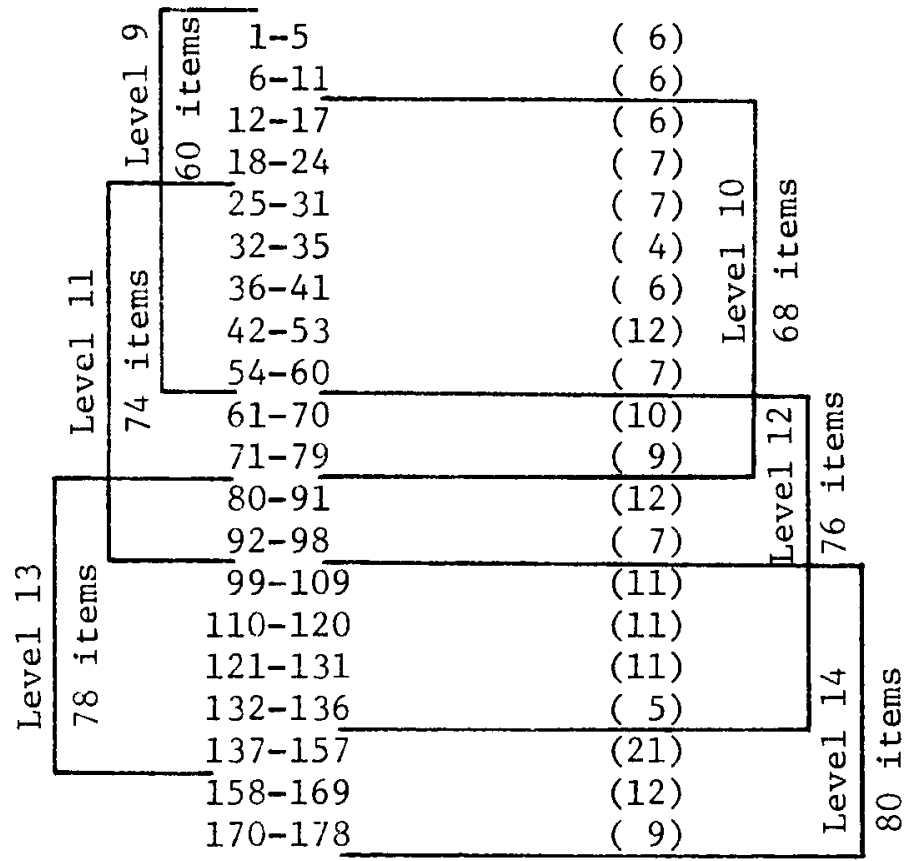

Table 2

The Mean and Standard Deviation

of the Index of Fit Statistic for Each Test Leve1

\begin{tabular}{rcc}
\hline Level & Mean & $\begin{array}{c}\text { Standard } \\
\text { Deviation }\end{array}$ \\
\hline 9 & .98 & .06 \\
10 & .97 & .06 \\
11 & .98 & .06 \\
12 & .99 & .05 \\
13 & .98 & .05 \\
14 & .98 & .07 \\
Expected Mean $=1.00$ & \\
Standard Error $=.045$ & \\
\hline
\end{tabular}


A cutoff for determining the goodness of fit for individual items can be calculated as the expected value of 1.00 plus three standard errors. In this case the cutoff was determined to be 1.14 . Inspection of the individual item fit mean square statistics indicated that only two items departed from the model by this criterion. These items were No. 42 (in Level 11) and No. 168 (in Level 14) with fit mean squares of 1.17 and 1.19 , respectively. Since the purpose of this study was to compare two methods for equating test scores rather than to develop or refine a measurement instrument, these two items were not removed from the test. Trimming the test by eliminating these two misfitting items is of no practical consequence in this instance, given that the 176 other items fit well.

\section{Linking}

The next step was to "link" the separate analyses of each level. As was evident in Table 1, many items on each level overlapped with other levels. Those items common to adjacent levels provided the basis for linking.

The Rasch model makes no assumptions about the distribution of abilities in the calibration samples. Therefore, each item in the test can be calibrated regardless of the ability distribution of the students taking the test as long as there is some score variance. The percent correct for an item may differ dramatically when answered by low ability students and by high ability students; but theoretically, the Rasch difficulty differences remain statistically invariant (i.e., within the error of the estimate). This remains true when items appear on different tests. Because a separate group of 1,000 students took each level, a pair of separate and independent estimates of difficulty was produced for each item common to any two test levels. The mean difference in these estimates for common items yielded the translation factor for equating each adjacent pair of test levels.

As an example of how these translation factors were determined, consider Levels 9 and 10 .
Level 9 consists of Items 1 through 60; Level 10 consists of Items 12 through 79 . There are 49 items common to both levels. According to the test authors, these 49 items represent the most difficult items of Level 9 but the easiest items in Level 10. The Rasch analysis calibrates items to a mean difficulty of zero within each test. If Level 10 is more difficult than Level 9, the zero point for Level 10 should be at a higher point on an overall calibration scale than the zero point for Level 9. This difference between these points is the translation factor between Level 9 and Level 10.

The translation factor can be calculated by comparing the estimated difficulties of the common items calibrated on both levels. In this case, the translation factor is determined by calculating the mean difference in estimated Rasch difficulty for the 49 items common to Level 9 and Level 10. A general expression for calculating the translation factor is

$$
t_{a b}=\sum_{i}^{k}\left(d_{i a}-d_{i b}\right) / \kappa
$$

where $d_{i a}$ and $d_{i b}$ are the estimated difficulties of item $i$ in test $a$ and test $b$, and $K$ is the number of common linking items. This is the constant necessary to translate all item difficulties in the calibration of test $b$ onto the scale of test $a$, or vice versa.

According to Wright (1977) each difficulty estimate has a standard error of about $2.5 / N^{1 / 2}$ logits, so that the translation factor $\left(t_{a b}\right)$ has a standard error of about $3.5 /(N K)^{1 / 2}$ logits, where $N$ is the number of persons in the calibration sample. The precision of this test link can be judged with the fit statistic $S_{a b}^{2} N K / 12$, which has an approximate chi-square distribution with $(K-1)$ degrees of freedom, where

$$
s_{a b}^{2}=\sum_{i}^{K}\left(d_{i a}-d_{i b}-t_{a b}\right)^{2} \text {. }
$$

\section{Results}

Using Equation 1, translation factors were calculated for each adjacent test level pair. These 
translation factors, together with their standard errors, are listed in Table 3. Also listed are the translation factors calculated by Rentz and Bashaw (1975) for several of the same levels of the ITBS.
Calculation of the translation factors may also be illustrated graphically. Figures 1 through 5 plot the estimated Rasch difficulties for items common to consecutive test levels. The solid line drawn on the graph indicates equal difficulty on

\section{Tabie 3 \\ Translation Factors and Standard Errors for Consecutive Test Level Pairs}

\begin{tabular}{rcccc}
\hline Levels & $\begin{array}{c}\text { Number of } \\
\text { Common Items }\end{array}$ & $\begin{array}{c}\text { Translation } \\
\text { Factor }\end{array}$ & $\begin{array}{c}\text { Standard } \\
\text { Error }\end{array}$ & $\begin{array}{c}\text { Rentz \& Eashav } \\
\text { Translation } \\
\text { ractor }\end{array}$ \\
\hline $9-10$ & 49 & .691 & .016 & \\
$10-11$ & 55 & .576 & .015 & .570 \\
$11-12$ & 38 & .980 & .018 & .733 \\
$12-13$ & 57 & .423 & .015 & \\
$13-14$ & 59 & .477 & .014 & \\
\hline
\end{tabular}

both levels. Assuming the upper level of a pair to be a more difficult test than the lower level, items common to the test levels would be the easier items on the upper level but the more difficult items on the lower level. Therefore, all of the points representing items would be expected to lie above this line. Items that lie on or below this line are those with apparent defects.

The dashed line drawn on each graph is a 45 degree line fitted to the plotted difficulties. This line illustrates how the data fit the model. It shows that there is continuity in the trait from top to bottom and that from level to level the dimensions measured by items are colinear across the test. The distance between the dashed line and the solid line, measured either vertically or horizontally (both scales are the same) is equivalent to the translation factor between those two levels of the test.

After calculating translation factors linking pairs of consecutive test levels, the next step was to calibrate all levels on a single scale for the entire test. This provided the means by which to compare the norm-referenced scale for equating scores from different test levels with the Rasch ability scale.
To express all measures on a single scale, the Rasch ability estimates were first listed for each raw score at each test level. These results had been obtained through the separate analysis of each level of the test. Then, centering on Level 11, the translation factors were used to adjust the ability estimates for raw scores on the other test levels. These adjusted Rasch ability estimates thus provided a single scaling for raw scores on each test level. A summary of adjusted Rasch ability estimates for scores on the various levels of the test is listed in Table 4. Level 11 was used to center the ability estimates only because it fell in the middle of the test range. Actually, any level could have been used. Although using another level would alter the scale origin, the interval nature of the scale would remain unchanged.

Having equated the Rasch ability estimates for each raw score on every level of the test, the final step was to compare these estimates with the norm-referenced, grade-equivalent estimates. The publishers of the ITBS provide a listing of estimated grade equivalents for each raw score across test levels. The Rasch ability estimates were plotted against these grade-equivalent esti- 


\section{Figure 1}

Comparison of Rasch Item Difficulties for Levels 9 and 10 (49 items, Numbers 12-60)

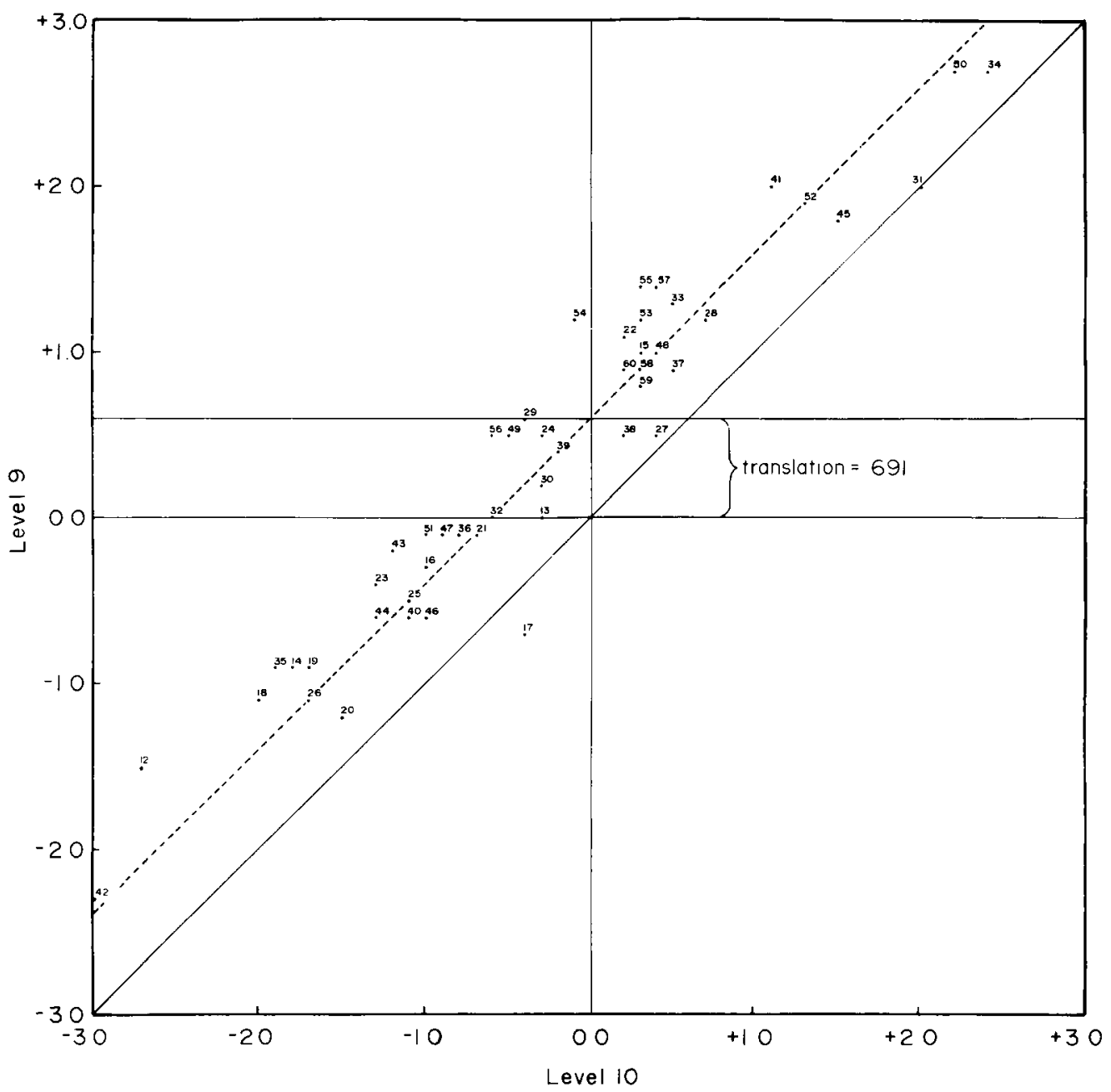

mates for raw scores on each test level. The results are shown in Figure 6. This plot shows that changes in grade equivalent correspond closely to changes in Rasch ability for middle range scores on all levels of the test. At the extreme scores for each level, however, Rasch ability estimates increase much more rapidly than the ITBS grade equivalents. This occurs because the Rasch test model, similar to all latent trait models, sets up linearity on the trait rather than on the test scores. Hence, at extreme scores the Rasch estimates go toward infinity, whereas the score-linear grade equivalents do not.

Particularly interesting in Figure 6 is that for a range of lower test scores, a substantial gap exists between the two scales regarding estimates on Levels 9, 10, and 11 of the test and Levels 12,13 , and 14 . That is, for this particular 


\section{Figure 2}

Comparison of Rasch Item Difficulties for Levels 10 and 11

(55 items, Numbers 25-79)

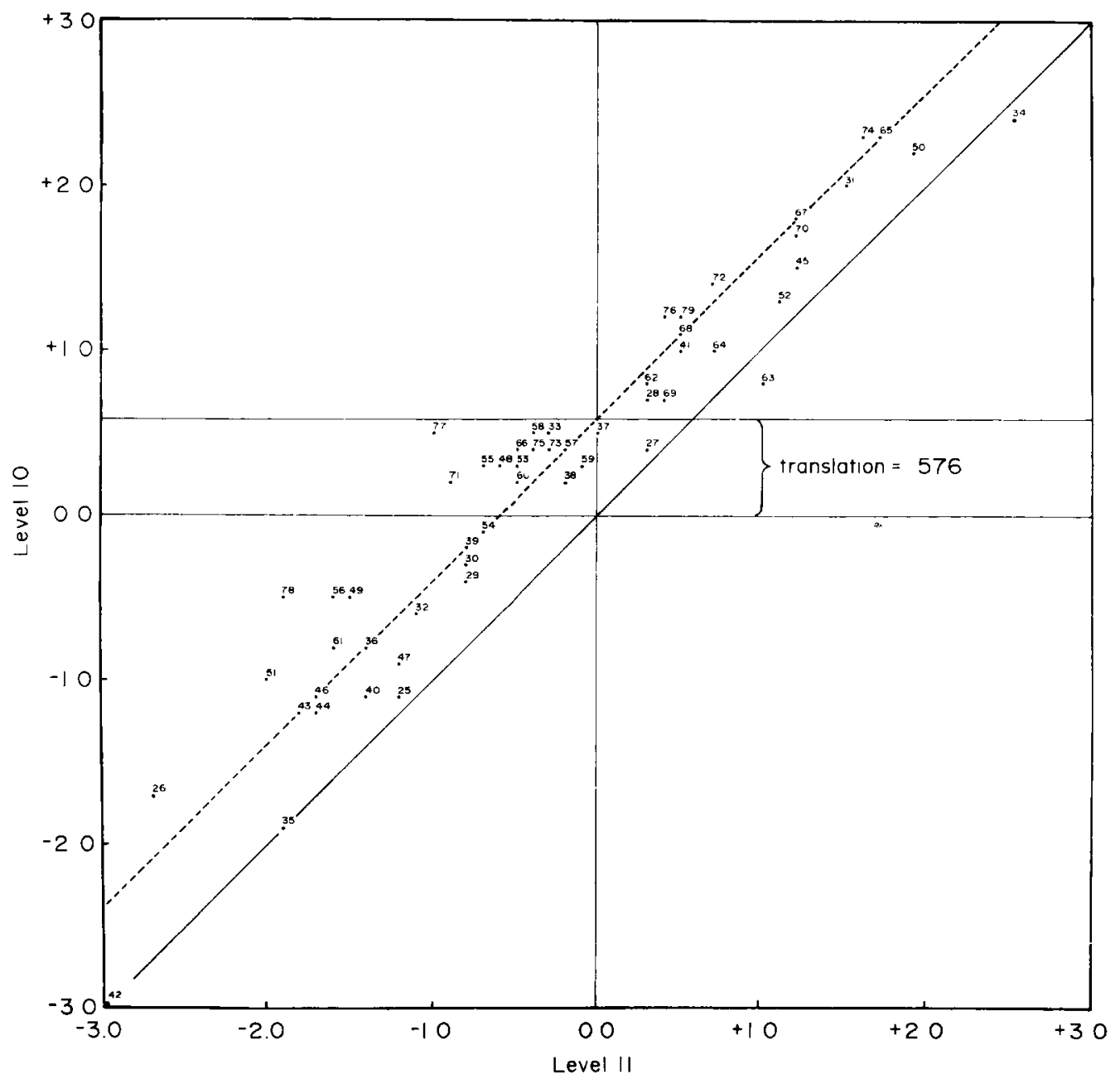

range of scores, students taking a lower level test (Levels 9, 10, or 11) and students taking an upper level test (Levels 12, 13, and 14) may be assigned the same ITBS grade equivalent (say 4.0), whereas estimates of their ability on the Rasch scale would differ by as much as a logit, a difference roughly equivalent to a whole grade level in this region. Along the other dimension, a stu- dent taking an upper level test may be assigned the same Rasch ability as a student taking a lower level test (say -1.0), differing as much as an entire year on the grade-equivalent scale. This relationship is illustrated more clearly in Figure 7.

In order to evaluate this rather large discrepancy between the different scale estimates 


\section{Figure 3}

Comparison of Rasch Item Difficulties for Levels 11 and 12 (38 items, Numbers 61-96)

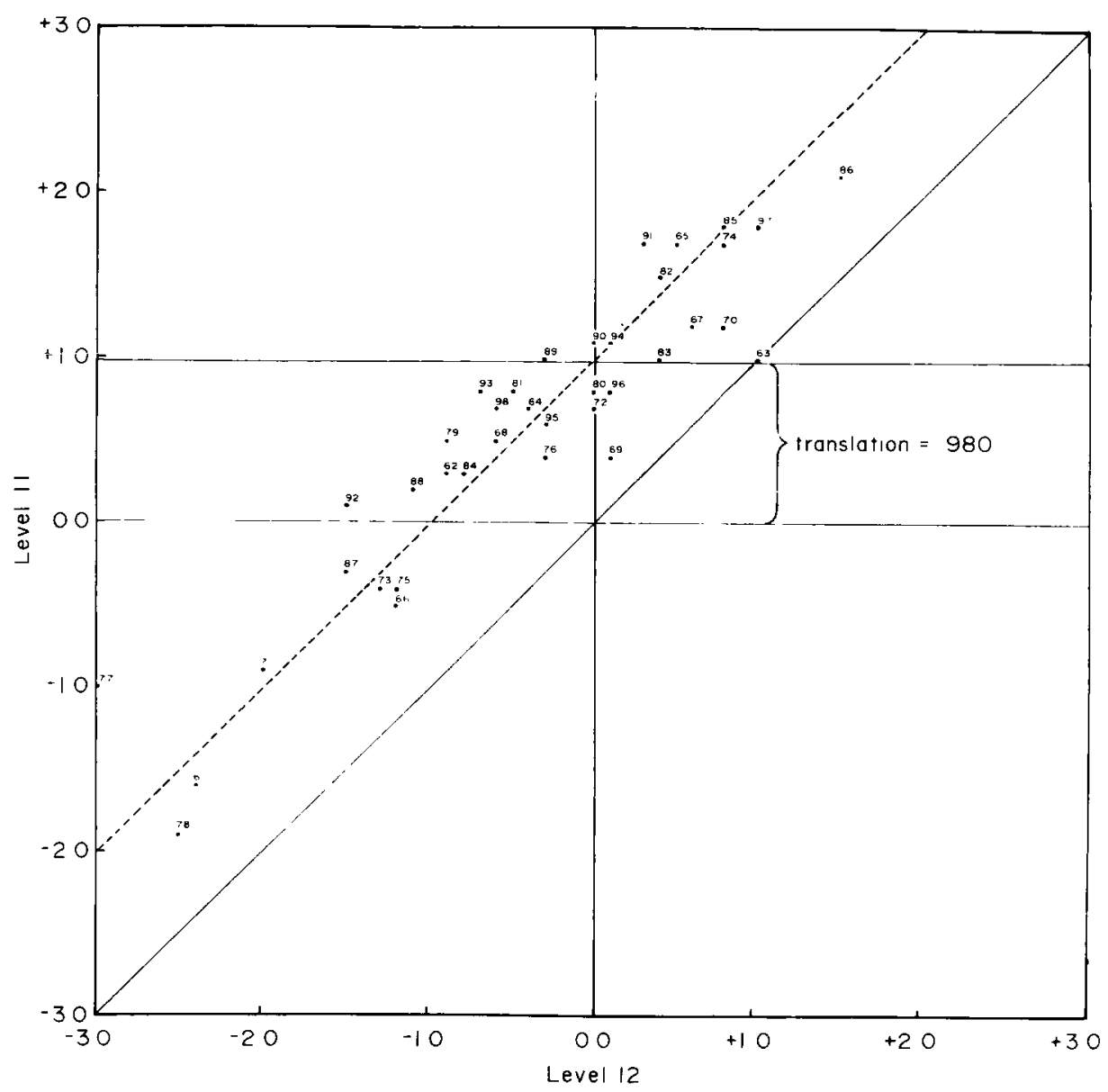

for scores near the fourth-grade level of the test, an additional round of data collection was begun, gathering information from other results of the 1976 citywide testing program. Groups of pupils were sought who had attained scores within the range of this discrepancy in the scale estimates.

Three critical points of discrepancy (labeled A, $B$, and $C$ on Figure 7) were identified. Point $A$ represents students who were administered a lower level test (Levels 9, 10, or 11) and scored at approximately 4.0 on the grade-equivalent scale in reading comprehension. Point $B$ represents students who were administered an upper level test (Levels 12, 13, and 14) and scored at approximately the same 4.0 on the grade-equivalent scale. Point $\mathrm{C}$ represents students who were administered an upper level test (Levels 12, 13, or 14) and scored at approximately 3.0 on the grade-equivalent scale.

The discrepancy between the two scaling systems in the fourth-grade range of scores, for 
Figure 4

Comparison of Rasch Item Difficulties for Levels 12 and 13

(57 items, Numbers 80-138)

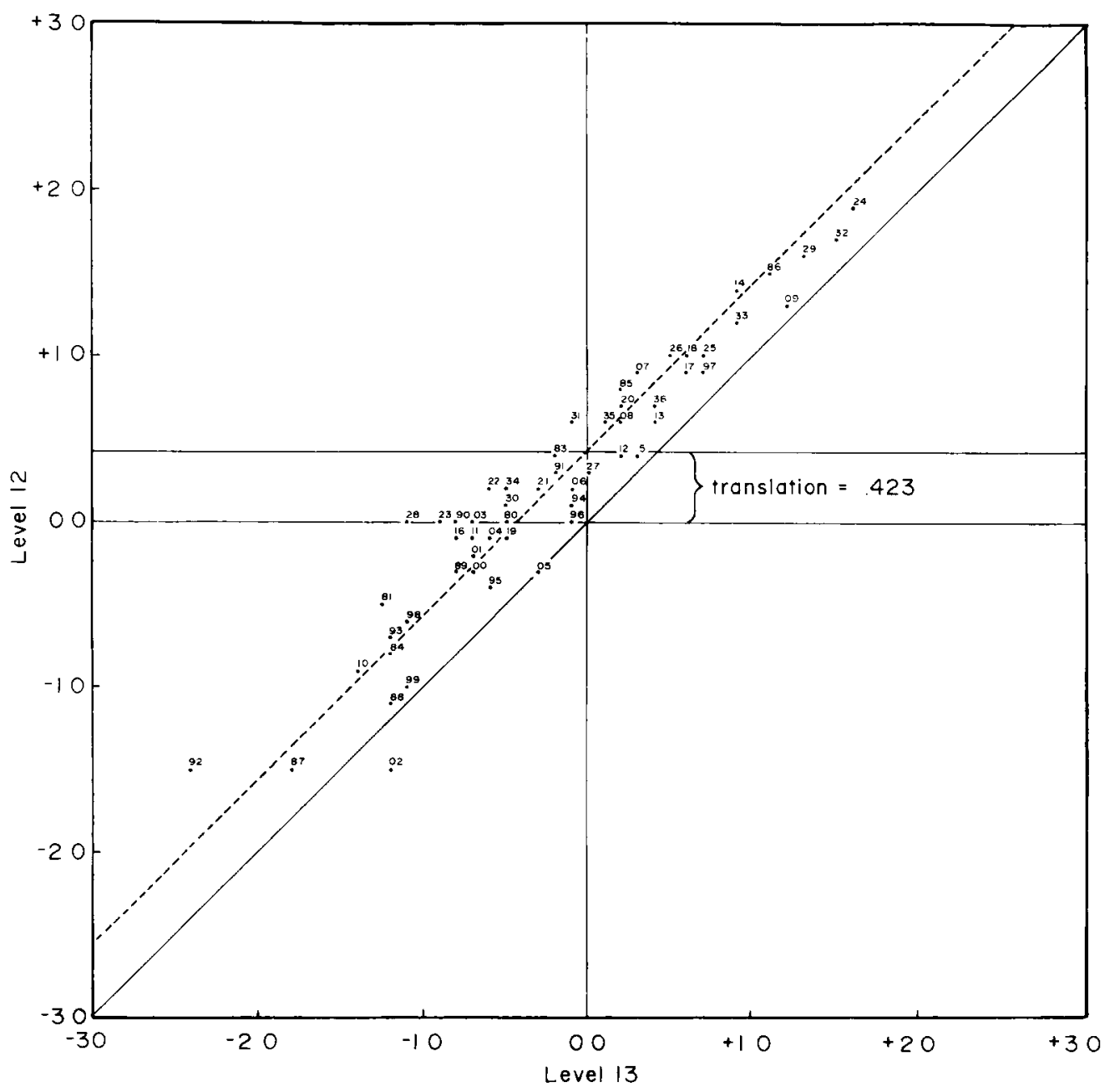

these levels of the test, may be summarized as follows: By the grade-equivalent scale, students at Point $\mathrm{A}$ and students at Point $\mathrm{B}$ have approximately the same reading comprehension ability; by the Rasch ability scale, however, students at Point $B$ have greater reading comprehension ability than do those at Point A. In contrast, by the grade-equivalent scale, students at Point $\mathrm{A}$ have greater reading comprehension ability than do students at Point $\mathrm{C}$, whereas by the Rasch ability scale they have approximately the same reading comprehension ability.

Having identified these three critical points, groups of pupils were selected who were administered these particular levels of the test and whose Reading Comprehension Test scores fell 
Figure 5

Comparison of Rasch Item Difficulties for Levels 13 and 14

(59 items, Numbers 99-157)

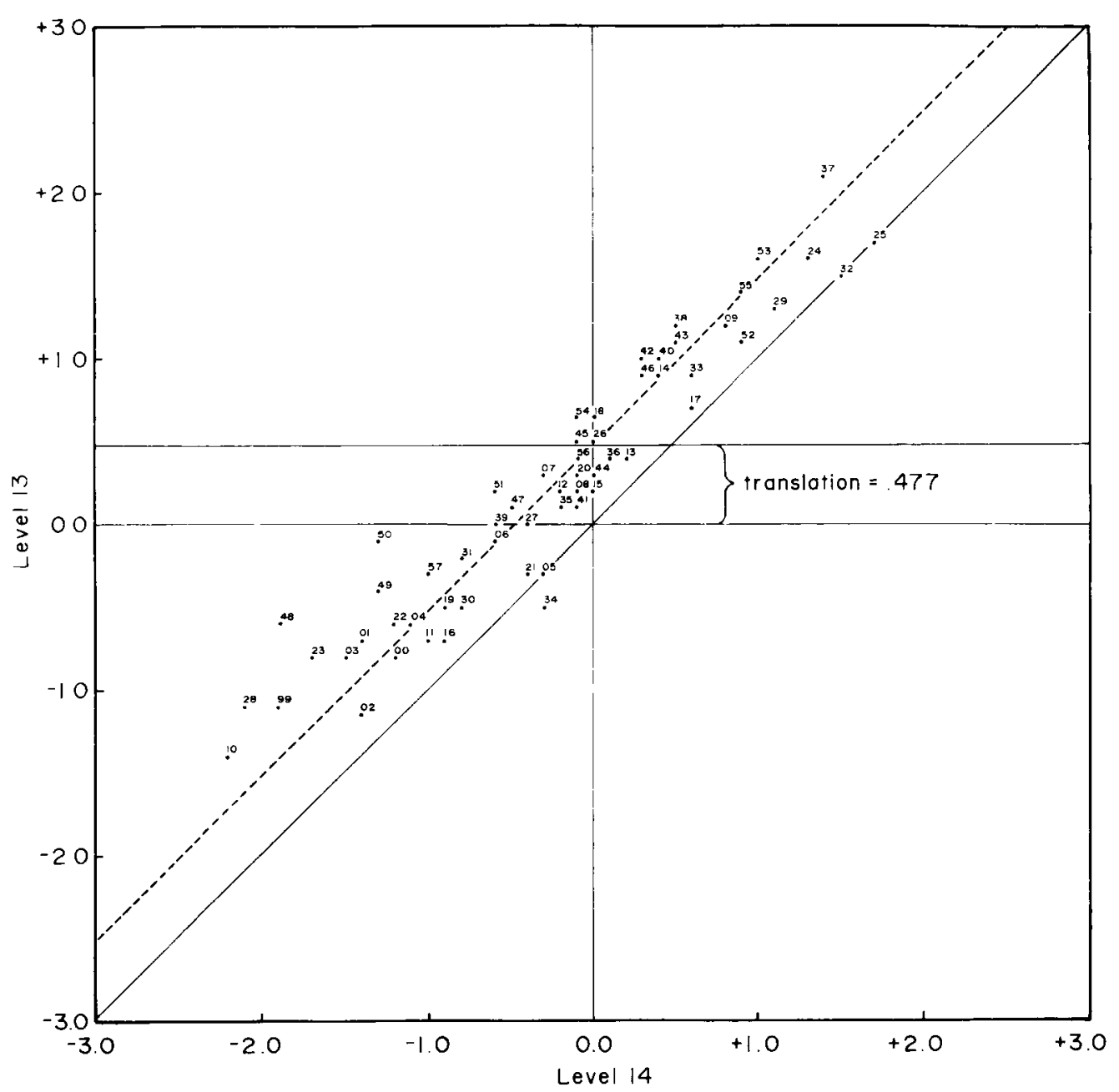

within a narrow range around these points $( \pm 0.5$ grade equivalents). All pupils in the city whose scores fell within this range were included in the sample. The mean scores for each of these groups of pupils on other tests from the ITBS battery were then tabulated. The results of these tabulations are listed in Table 5.

The three other test scores that were collected for pupils whose reading comprehension scores fell within this narrow range for the particular test level were from the Reading Vocabulary Test, the Mathematics Concepts Test, and the Mathematics Problem-Solving Test. The test publishers report that scores on these tests are all highly correlated with scores on the Reading Comprehension Test. Correlations range from .75 to .82 with various levels of the Reading Vocabulary Test, from .67 to .73 with the Mathe- 
Table 4

Adjusted Rasch Log Ability Per Raw Score for Each Level

\begin{tabular}{|c|c|c|c|c|c|c|}
\hline \multirow[t]{2}{*}{ Score } & \multicolumn{4}{|c|}{ Level } & \multirow[b]{2}{*}{13} & \multirow[b]{2}{*}{14} \\
\hline & 9 & 10 & 11 & 12 & & \\
\hline 1 & -6.44 & -5.80 & -5.38 & -4.01 & -3.49 & -3.22 \\
\hline 3 & -5.00 & -4.40 & -3.97 & -2.71 & -2.22 & -1.91 \\
\hline 6 & -4.05 & -3.48 & -3.04 & -1.86 & -1.40 & -1.05 \\
\hline 9 & -3.47 & -2.91 & -2.48 & -1.34 & -.89 & -.53 \\
\hline 12 & -3.03 & -2.49 & -2.04 & -.95 & -.52 & -.15 \\
\hline 15 & -2.66 & -2.15 & -1.72 & -.64 & -.21 & .17 \\
\hline 18 & -2.34 & -1.85 & -1.42 & -.37 & .05 & .44 \\
\hline 21 & -2.05 & -1.58 & -1.16 & -.13 & .28 & .67 \\
\hline 24 & -1.78 & -1.33 & -.92 & .09 & .49 & .89 \\
\hline 27 & -1.52 & -1.10 & -.69 & .29 & .68 & 1.09 \\
\hline 30 & -1.27 & -.87 & -.48 & .49 & .87 & 1.28 \\
\hline 33 & -1.02 & -.65 & -.27 & .67 & 1.05 & 1.47 \\
\hline 36 & -.76 & -.43 & -.07 & .86 & 1.23 & 1.65 \\
\hline 39 & -.49 & -.21 & .14 & 1.04 & 1.40 & 1.82 \\
\hline 42 & -.20 & .01 & .34 & 1.22 & 1.57 & 2.00 \\
\hline 45 & .12 & .25 & .55 & 1.41 & 1.75 & 2.17 \\
\hline 48 & .49 & .51 & .77 & 1.60 & 1.93 & 2.35 \\
\hline 51 & .93 & .78 & 1.00 & 1.80 & 2.12 & 2.54 \\
\hline 54 & 1.51 & 1.09 & 1.24 & 2.02 & 2.31 & 2.73 \\
\hline 57 & 2.46 & 1.46 & 1.52 & 2.25 & 2.52 & 2.94 \\
\hline 60 & & 1.92 & 1.82 & 2.51 & 2.75 & 3.16 \\
\hline 63 & & 2.56 & 2.19 & 2.80 & 3.01 & 3.41 \\
\hline 66 & & 3.76 & 2.64 & 3.16 & 3.32 & 3.69 \\
\hline 69 & & & 3.29 & 3.62 & 3.69 & 4.02 \\
\hline 72 & & & 4.49 & 4.32 & 4.20 & 4.45 \\
\hline 75 & & & & 5.97 & 5.02 & 5.04 \\
\hline 78 & & & & & & 6.16 \\
\hline
\end{tabular}

matics Concepts Test, and from .60 to .68 with the Mathematics Problem-Solving Test. Given the high positive intercorrelations among these tests, Reading Comprehension Test scores would be expected to be quite similar to scores on these other tests. With this expectation, the scores of students at each of the three critical points were compared by analysis of variance procedures with pairwise contrasts.

The differences between scores of pupils at Point $\mathbf{A}$ and pupils at Point $\mathbf{B}$ on these other tests, as indicated in Table 5 , suggest that the
ITBS reading comprehension grade-equivalent scores for pupils at Point $B$ are perhaps underestimates of their actual reading comprehension ability. The lack of differences between scores of pupils at Point $A$ and pupils at Point $C$ on these other tests suggests a similar conclusion: that is, that the ITBS reading comprehension gradeequivalent scores of pupils at Point $\mathrm{C}$ are also underestimates. An alternative explanation for these differences, however, is that they are largely due to different amounts of regression. That is, due to regression the means on tests other 
Figure 6

Grade Equivalents Versus Rasch Abilities for Raw Scores on All Test Levels

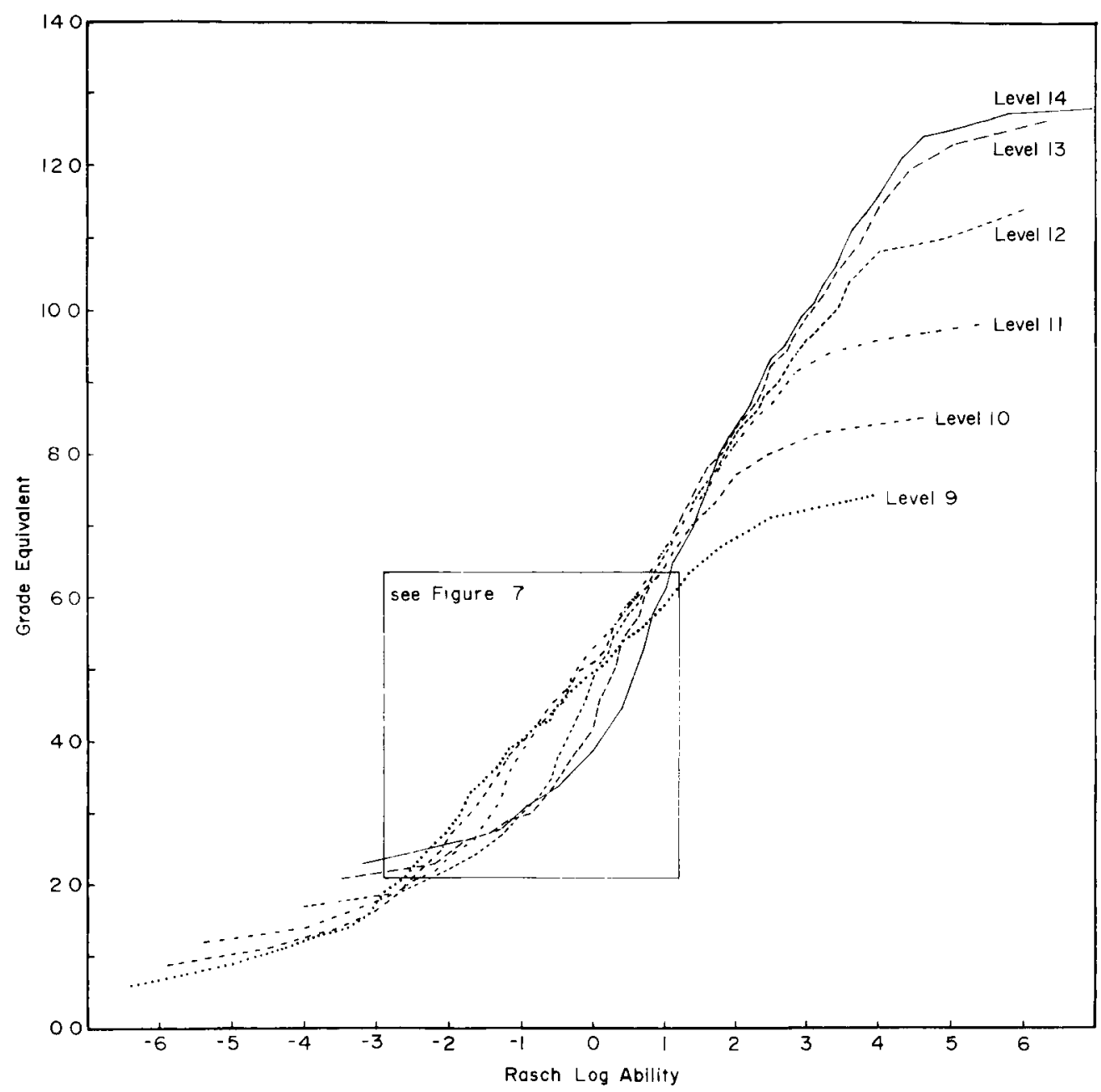

than Reading Comprehension are likely to move toward the grand mean for that specific test level. The amount of this regression would be a function of both differences between the reading comprehension mean for the selected subsample and the grand mean for that age group (level of test), and the correlation between the Reading Comprehension Test and the other selected test.

To explore this possibility, predicted means due to the effects of regression were calculated for each of the selected tests at each level. These predicted values were then compared to the values obtained from the data. The results of these comparisons, illustrated in Table 6 , show that in every case the obtained value exceeded that which was predicted for each test. At Point $B$, all but one of these differences was statistically significant. At Point $C$, three of the six differences met the criteria of statistical significance. Those that did not were comparable in magni- 


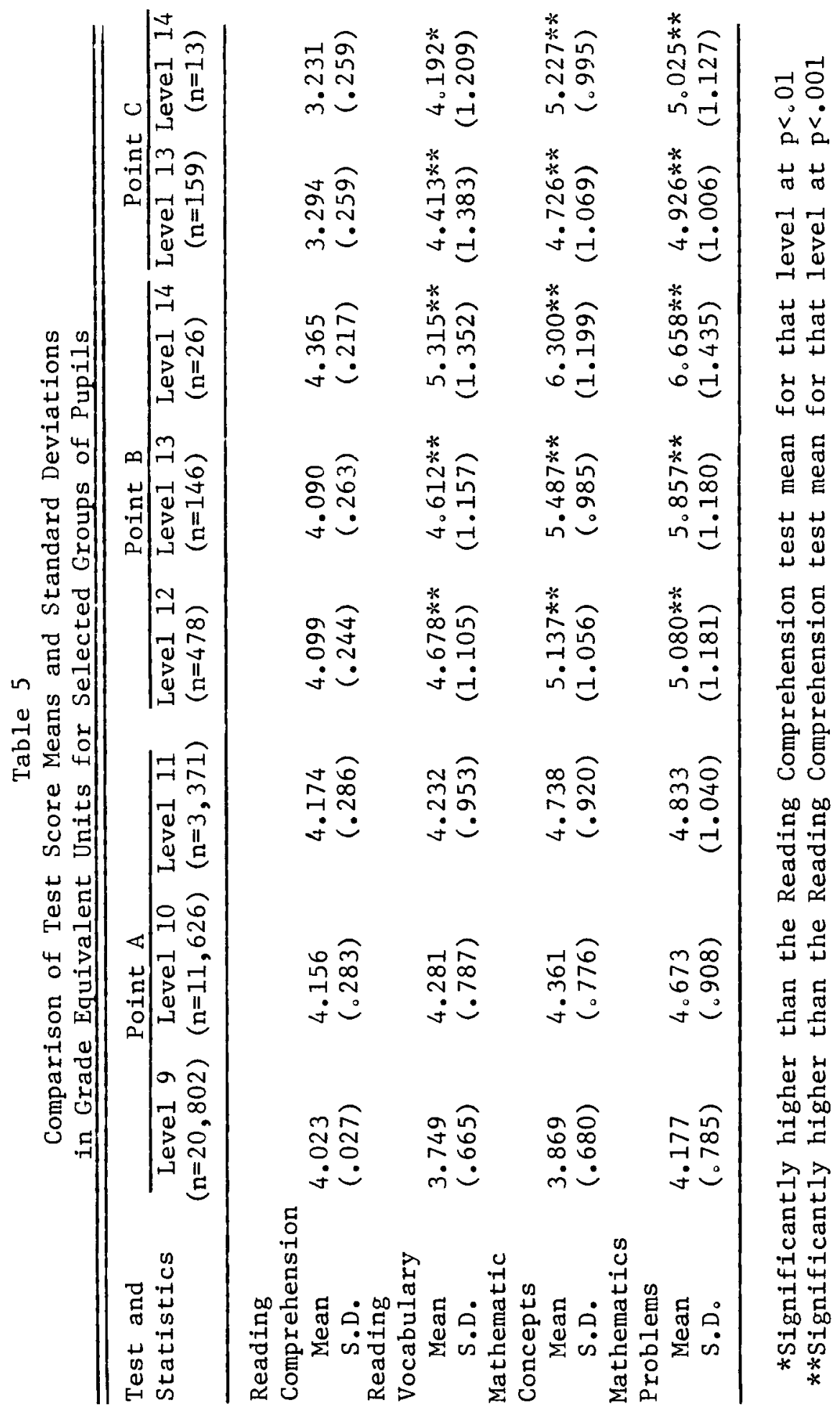




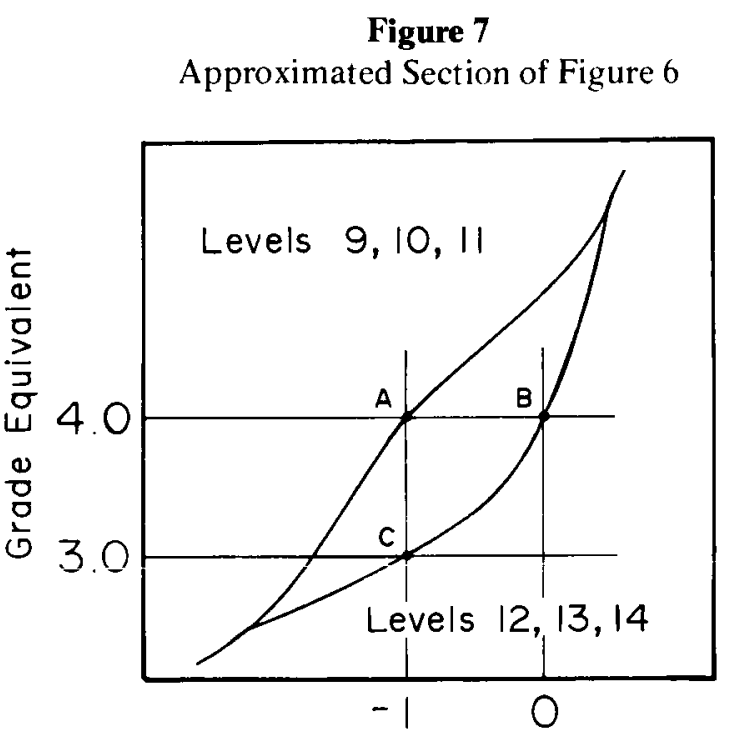

Rasch Log Ability tude to the others but were derived from a much smaller subsample $(n=13)$. These comparisons present strong evidence that the grade-equivalent scores are underestimates within this range of scores and that the Rasch ability scale may provide a more accurate estimate of reading comprehension ability.

\section{Summary And Conclusions}

The purpose of this study was to explore the utility of Rasch model procedures for vertical equating. The results obtained indicate (1) that Rasch procedures can be applied in a practical testing situation, (2) that the requirements for application of the model can be evaluated, and (3) that the outcomes can help to resolve measurement problems with perhaps greater accuracy than traditional methods provide.

Tatle $o$

Comparisons of Predicted lleans Due to Regression

\begin{tabular}{|c|c|c|c|c|c|c|}
\hline $\begin{array}{l}\text { Figure } 7 \\
\text { Peference } \\
\text { Point }\end{array}$ & $\begin{array}{l}\text { Test } \\
\text { level }\end{array}$ & & $\begin{array}{l}\text { Test } \\
\text { Srand } \\
\text { Tean }\end{array}$ & $\begin{array}{l}\text { Selected } \\
\text { Subsample } \\
\text { Nean }(Y)\end{array}$ & $\begin{array}{l}\text { Predicted } \\
\text { Test } \hat{N} \\
\text { Mean }(\hat{Y})\end{array}$ & $\begin{array}{c}\text { Difference } \\
(\mathrm{Y}-\hat{\mathrm{Y}}) \\
\end{array}$ \\
\hline B & $12 \mathrm{VOC}$ & & 6.08 & 4.678 & 4.257 & $-.421 *$ \\
\hline B & 12 Nath & Con & 6.21 & 5.137 & 4.878 & $-.259 *$ \\
\hline B & 12 Math & Pbs & 6.09 & 5.080 & 4.806 & $-.274 *$ \\
\hline B & $13 \mathrm{VOC}$ & & 7.06 & 4.612 & 4.491 & -.121 \\
\hline$B$ & 13 Math & Con & 7.22 & 5.487 & 5.281 & $-.206 *$ \\
\hline$B$ & 13 Nath & Pbs & 7.06 & 5.857 & 5.239 & $-618 *$ \\
\hline$B$ & $14 \mathrm{VOC}$ & & 3.02 & 5.315 & 4.862 & $-.453 *$ \\
\hline B & 14 Math & Con & 8.22 & 6.300 & 5.637 & $-.663 *$ \\
\hline B & 14 Math & Pbs & 7.94 & 6.558 & 5.507 & $-1.151 *$ \\
\hline C & 12 Voc & & 6.08 & 4.413 & 3.563 & $-.850 *$ \\
\hline $\mathrm{C}$ & 12 Math & Con & 6.21 & 4.726 & 4.370 & $-.356 *$ \\
\hline C & 12 Math & $\mathrm{Pbs}$ & 6.09 & 4.926 & 4.318 & $-.608 \%$ \\
\hline $\mathrm{C}$ & $13 \mathrm{Voc}$ & & 7.06 & 4.192 & 3.829 & -.363 \\
\hline C & 13 rath & Con & 7.22 & 5.227 & 4.781 & -.446 \\
\hline $\mathrm{C}$ & 13 Math & Pbs & 7.06 & 5.025 & 4.770 & -.255 \\
\hline
\end{tabular}

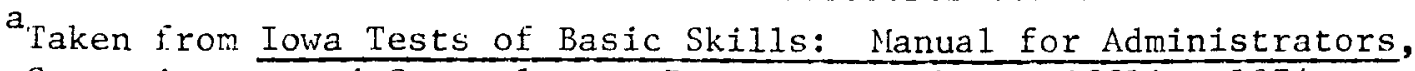
Supervisors, and Counselors. Boston: Houghton Mifflin, 1974. $* \mathrm{p}<.05$ 
Throughout the range of test scores, the Rasch ability estimates were found to be at least as precise as the grade-equivalent estimates and were perhaps the more precise estimate where discrepancies were found to exist. Both the Rasch item calibrations and the derived Rasch ability scale were consistent and stable across test levels. These results support the feasibility of increasing scaling efficiency through the use of Rasch analysis techniques and also provide a model for the cross-validation of other test-scaling and score-equating procedures.

\section{References}

Angoff, W. H. Scales, norms, and equivalent scores. In R. L. Thorndike (Ed.), Educational measurement. Washington DC: American Council on Education, 1971.

Mead, R. J. Assessing the fit of the data to the Rasch model through analysis of residuals. Unpublished doctoral dissertation, University of Chicago, 1976.

Rentz, R. R., \& Bashaw, W. L. Equating reading tests with the Rasch model. Vol. 1: Final Report. Vol. 2: Technical Reference Tables. Athens GA: University of Georgia, Educational Research Lab. oratory, 1975.

Wright, B. D. Sample-free test calibration and person measurement. In Proceedings of the $1967 \mathrm{In}$. vitational Conference on Testing Problems. Princeton NJ: Educational Testing Service, 1968.
Wright, B. D. Solving measurement problems with the Rasch model. Journal of Educational Measurement, 1977, 14, 97-116.

Wright, B. D., \& Mead, J. BICAL: Calibrating items and scales with the Rasch model (Research Memorandum No. 23). Chicago IL: University of Chicago, Department of Education, Statistical Laboratory, 1977.

Wright, B. D., Mead, R. J., \& Draba, R. Detecting and correcting test item bias and a logistic response model (Research Memorandum No. 22). University of Chicago, Department of Education, Statistical Laboratory, 1976.

Wright, B. D., \& Douglas, G. A. Best test design and self-tailored testing (Research Memorandum No. 19). University of Chicago, Department of Education, Statistical Laboratory, 1975.

\section{Acknowledgments}

The author expresses thanks to Michael Katims and Khazan Agrawal of the Department of Research and Evaluation, Chicago Board of Education, for their assistance in the development of this research. and to Benjamin D. Wright of the University of Chicago for his helpful comments.

\section{Author's Address}

Send requests for reprints or further information to Thomas R. Guskey, College of Education, University of Kentucky, Lexington KY 40506. 